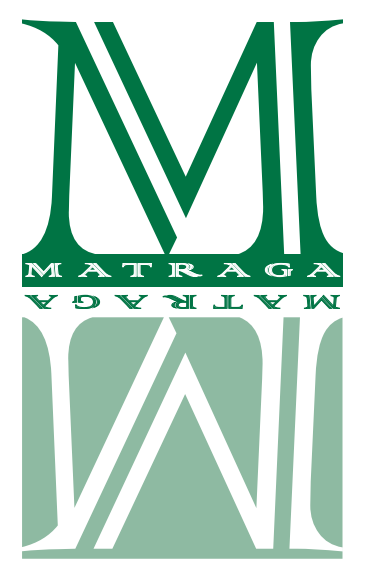

\title{
0 ensino de língua inglesa na pandemia atravessado pela materialidade digital: uma análise discursiva
}

\author{
Gustavo Haiden de Lacerda \\ Universidade Estadual de Maringá (UEM) \\ http://orcid.org/0000-0002-0470-7543 \\ Nelci Alves Coelho Silvestre \\ Universidade Estadual de Maringá (UEM) \\ https://orcid.org/0000-0002-6670-2326
}

\begin{abstract}
RESUMO
Neste artigo, refletimos acerca de uma experiência de ensino de língua inglesa durante estágio supervisionado, em meio à pandemia de COVID-19. O objetivo central foi compreender implicações de ordem social e discursiva relacionadas ao atravessamento do digital em aulas de inglês. Para tanto, analisamos alguns dos desafios e das possibilidades do ensino remoto de línguas, por meio do referencial teórico-metodológico da Análise de Discurso, com base na experiência de professor-em-formação de língua inglesa e nos comentários de alguns alunos a respeito das aulas online. O percurso analítico fez notar a necessidade de um processo metafórico sobre os instrumentos de ensino para produzir efeitos significativos sobre a prática docente e sobre as vivências dos alunos.
\end{abstract}

Palavras-chave: Ensino remoto; Língua inglesa; COVID-19; Análise de Discurso

\section{English Language Teaching During The Pandemic Intersected by The Digital Materiality: A discursive analysis}

\section{ABSTRACT}

In this paper, we reflect upon an ESL experience in a language teaching course, amidst the COVID-19 pandemic. The main objective was to comprehend social and discursive implications brought about by digital apparatuses in English lessons. In order to do so, we analyzed some of the challenges and possibilities of remote English teaching, grounded on the theoretical and methodological framework of Discourse Analysis, based on the experience as English teacher-to-be and on students' comments about online classes. The analytical trajectory pointed out to the necessity of a metaphoric process upon teaching instruments so that significant effects on educators' practices and on students' experiences can be produced.

Keywords: Remote Teaching; English Language; COVID-19; Discourse Analysis 


\section{Introdução}

Com a chegada e a decorrente disseminação do novo coronavírus em território brasileiro, desde o início de 2020, novos desafios para o ensino foram somados àqueles que já existiam em condições típicas. No que tange ao ensino de língua inglesa (doravante LI), as dificuldades de ensinar uma língua estrangeira são intensificadas pelos impedimentos de interação em aulas pré-gravadas e mesmo em chamadas síncronas, que também não favorecem de todo a interlocução.

Se problemas despontam, lados positivos não deixam de aparecer, como a possibilidade de implementação de metodologias de ensino e aprendizagem multimodais, explorando-se recursos digitais. Encaminhar links, enviar imagens, propor jogos interativos e quizzes online, entre outras ferramentas, aparecem como formas de repensar instrumentos de ensino de LI.

Entre desafios e possibilidades, é inegável que o processo de ensinar e aprender é ressignificado pela mediação eletrônica. Neste texto, propomos atentar para alguns dos modos de ressignificação dessas novas formas de ensinar, com o objetivo de entender em que medida o digital (re) significa as práticas de ensino e aprendizagem de língua inglesa. Para isso, dividimos este artigo em três seções: a primeira recupera um breve panorama do ensino a distância e as condições em que se realiza durante a pandemia do novo coronavírus; a segunda explicita as bases teóricas de nossa análise, bem como a descrição metodológica; a terceira, do gesto analítico propriamente, envolve a consideração de comentários de alunos que englobam aspectos positivos e negativos do ensino de LI a distância, permeados pela experiência de professor-em-formação.

\section{Sobre o ensino remoto emergencial em tempos de pandemia}

A recomendação comum das autoridades de saúde é a de que a melhor forma de prevenção é o distanciamento físico, como forma de evitar a circulação do vírus. Em São Paulo, em 23 de março de 2020, a Secretaria de Saúde do estado junto ao governo estadual e a Secretaria de Educação suspendeu as aulas presenciais por tempo indeterminado, e agora (novembro) a maioria das escolas do estado decidiu pelo retorno gradual somente a partir de janeiro de 2021, quando se espera que uma primeira remessa da vacina seja aplicada na região ${ }^{1}$. Em nível de Brasil, o Ministério da Educação, em colaboração com o Conselho Nacional de Educação (CNE), aprovou diretrizes para orientar as práticas docentes em tempos de pandemia, cuja pauta principal foi em torno do calendário letivo de $2020^{2}$.

Nesse cenário, o ensino remoto emergencial aparece como meio de manter as aulas e respeitar o distanciamento promulgado. Ressaltamos, de início, o adjetivo "emergencial", que deixa claro que se trata de uma situação fora do comum, um caso de exceção, que pede por medidas

\footnotetext{
${ }_{1}$ Disponível em: <https://www.redebrasilatual.com.br/educacao/2020/10/reabertura-escolas-sao-paulo/>. Acesso em 20 nov. 2020.

2 Disponível em: <http://portal.mec.gov.br/busca-geral/12-noticias/acoes-programas-e-projetos-637152388/89051-cne-aprova-diretrizes-para-escolas-durante-a-pandemia>. Acesso em: 23/12/2020.
} 
paliativas. E isso é significativo, pois as discussões a respeito da implantação de ensino a distância na estrutura educacional brasileira se intensificam, tanto com argumentos em defesa quanto em questionamento. Embora essas reflexões sejam relevantes, é importante entender que não estamos passando por um momento típico e medidas que visem a expansão do EaD devem ser tomadas com cautela.

Em seu formato mais primitivo, o EaD surgiu no início do século XX e popularizou-se após a Segunda Guerra Mundial. Sua expansão se deu atrelada à capacitação de mão de obra para o trabalho. Conforme Moore e Keasley (1996), em um primeiro momento, até a década de 1960, o EaD funcionava através de correspondência, por meio de materiais impressos, como apostilas e guias de estudos, que mediavam a interlocução entre o aprendente e o tutor. Isso começou a modificar-se a partir de 1970, com a popularização da televisão, a qual permitiu que o EaD não se restringisse ao papel, mas passasse a ser divulgado televisivamente, originando os telecursos.

A internet, no início dos anos 1990, mas principalmente depois de 2000, com o desenvolvimento da web 2.0 (DIAS, 2004), revolucionou mais uma vez o EaD, especialmente por permitir a realização de aulas síncronas, que favoreceriam a interação entre professores e alunos, bem como de alunos com alunos, em tempo real. Junto a isso, o EaD mediado pela internet fez aumentar as formas multimídias no processo, em sintonia com as tendências de multiletramento.

Porém, é importante diferenciar o EaD (como modalidade educacional) do ERE (ensino remoto emergencial). Conforme Saraiva et al. (2020), o EaD tem foco em resultados e avaliações, enquanto o ensino remoto se concentra no desenvolvimento de atividades menos avaliativas, dando mais atenção ao gerenciamento de tempo. Por exemplo, no ERE síncrono, há um horário a ser cumprido para a reunião da turma por meio de uma plataforma selecionada, como Google Meet ou Zoom.

Ainda que o ERE não se confunda com o EaD, não caminha longe. Ambos funcionam pela mediação tecnológica eletrônica e pelo cumprimento de atividades também assíncronas. O que nos parece relevante na distinção, como comentado, é o caráter de emergência, que faz lembrar que se está lidando com um método mitigador para suprir uma necessidade momentânea, imposta pelo COVID-19.

É inegável, de qualquer forma, que vivenciamos mudanças profundas no formato já secular da educação. Em conformidade com E. Grigoletto (2011a), o velho discurso pedagógico, em suas bases seculares, passa a ser atravessado pelo discurso das novas tecnologias, e isso instaura uma nova discursividade, novos modos de produzir sentido.

No país onde ecoa a máxima de que "a economia não pode parar", coerente com um discurso capitalista, ao passo que se desconsideram muitas vezes as vidas em jogo, outra máxima, agora no âmbito escolar, pode ser depreendida em paráfrase: "a escola não pode parar". O argumento, explicam Saraiva et al. (2020), desde o início da pandemia, era o de que ficar sem aulas representaria um dano sério à aprendizagem dos estudantes. Dano também às 800 horas do ano letivo, tão reiteradas em pronunciamentos públicos sobre o assunto. Não se pode perder tempo, muito menos parar. Foi assumindo o risco de produzir outros danos, na esperança de que fossem menores, que a proposta do ensino remoto emergencial foi implementada no território nacional. 
Isso recupera uma memória para o ensino, aqui fortemente atrelado ao discurso capitalista da produtividade a todo custo, sendo a queda dessa produtividade significada como um impossível de uma tal formação social. A redução do ato de ensinar é nítida, limitada à capacitação para o mercado de trabalho e para o cumprimento de horas. Se esses sentidos já circulam em condições normais, são agora intensificados pela entrada de peso das novas tecnologias, que reforçam essa necessidade construída.

Colateralmente, a pandemia veio desnudar desigualdades arraigadas na educação brasileira e chamar nossa atenção para a importância de políticas públicas direcionadas a grupos mais vulneráveis. Se o ensino já tende a ser excludente, a mediação virtual apenas reforça isso. Ciente desse problema, a Unesco já faz apelos às nações para planejamentos educacionais que auxiliem na contenção das desigualdades que sem dúvida se imporão com o COVID-19. Segundo a agência da ONU, o impacto da evasão escolar será grande, os números tendem a aumentar nesta década, considerando a recessão econômica que está por vir.

Nosso gesto analítico esmiuçará as problemáticas despontadas até aqui. Partimos do pressuposto de que introduzir novas tecnologias nas aulas de LI não é benéfico por si mesmo. É preciso uma apropriação, como será explicado.

\section{Referencial teórico e procedimento metodológico}

As análises que seguem têm como suporte teórico-metodológico os dispositivos e procedimentos da Análise de Discurso materialista (AD), que reconhece em Michel Pêcheux (1990; 1995) e em Eni Orlandi (2005; 2008) autores fundantes. O objetivo de uma análise discursiva é detectar gestos de interpretação inscritos na discursividade (PÊCHEUX, 1990), bem como "distinguir quais gestos de interpretação estão na base da produção de sentidos de um texto" (ORLANDI, 2005, p. 28).

Uma das principais contribuições da $\mathrm{AD}$ está no fato de pensar a língua em sua autonomia relativa (PÊCHEUX, 1995), ou seja, como a base material comum para a realização de diferentes processos discursivos, afetada pela história. Para produzir sentidos, é preciso que a língua - aberta a falhas - inscreva-se na história - em suas contradições: a isso denomina-se "discurso". Ao afirmar que a língua não se dissocia da história, é assumida a potência da linguagem enquanto prática discursiva, ação simbólica (significante e significativa) que intervém no real dos sentidos.

Ressignificar o que se assume por língua terá efeitos naquilo que a $\mathrm{AD}$ concebe como ensino de línguas. Em uma abordagem discursiva, o ensino de LI vai além de uma abordagem comunicacional, uma vez que não basta "dominar" um idioma e as competências linguísticas (DE NARDI, 2009). Entendemos que há saberes necessários para além do nível estritamente linguístico, que envolvem questões sociais, culturais e econômicas.

Assim, evitamos falar em competência para não recuperar a ideia de um sujeito consciente e dono de seu dizer. Seria imaginar a interação como uma situação feliz de interrelação, outorgando à língua a função de instrumento comunicacional. Uma tal abordagem não coincide com a visão de sujeito em $\mathrm{AD}$, como um ser de linguagem, constituído duplamente pela ideologia 
e pelo inconsciente (ORLANDI, 2005). A língua, em AD, serve também para não comunicar, assinalava Pêcheux (1995). Como espaço de contatos e conflitos, a língua é o meio material de disputas por sentidos.

Ao estudar os papéis atribuídos e assumidos pelas escolas e pelos alunos no processo de ensino de línguas, M. Grigoletto (2012) aponta que a instituição escolar reproduz o discurso da aplicação imediata de saberes utilitários, destinando ao aluno a posição de sujeito pragmático, "usuário" desses saberes. Esse ponto será retomado na seção que segue, mas já adiantamos que um risco do ensino remoto é o de reforçar ainda mais o ensino como consumo para futura aplicação no mercado. Ao sustentar um imaginário de participação no mundo globalizado, o ensino de LI tende a desconsiderar a dimensão educacional em si.

No que se refere aos procedimentos metodológicos do gesto analítico, de caráter qualitativo, consideramos aulas que foram ministradas no ensino privado de forma individual, o que permitiu dar atendimento individualizado. As aulas foram síncronas, ou seja, ao vivo, mediadas por chamadas de vídeo via WhatsApp ou Google Meet, a depender da preferência dos estudantes.

O público dessas aulas foi bastante diverso, constando homens e mulheres, entre 16 e 35 anos, de diferentes backgrounds e com variados níveis de conhecimento de LI. As quatro aulas assistidas pela docente de estágio foram para duas estudantes: duas aulas foram destinadas a uma jovem de 16 anos, aluna de ensino médio, que faz curso de inglês com o objetivo de realizar provas de vestibular. As outras duas aulas em destaque foram para uma aluna de 20 anos, universitária, cujo principal objetivo era estudar para poder provar proficiência em um programa de intercâmbio do qual desejava participar ${ }^{3}$. Para descrição geral, acrescentamos que os demais alunos, em termos profissionais, são uma estudante de economia, um auxiliar administrativo e uma médica veterinária.

No entanto, é importante frisar que não será discutido, no espaço deste texto, o conteúdo das aulas enquanto tal, mas a maneira com que esse conteúdo foi afetado pela materialidade do ERE. O instrumento de coleta de material foi um questionário aberto (por meio do Google Forms), de modo que o ponto de partida das análises fosse os comentários tecidos pelos alunos acerca do ensino não-presencial, com a questão motivadora adiante. O questionário foi enviado a 12 alunos, mas apenas cinco responderam a tempo da escrita do presente artigo. Com base nesses retornos, interviemos com nossa experiência de professor-em-formação. Seguindo a reflexão de Calvo et al. (2009), a pesquisa com sujeitos por meio de questionário aberto permite apreender as maneiras com que as ações sociais significam para eles sem impor limitações nas respostas.

Ao serem questionados, pelo professor-estagiário, em uma questão aberta, sobre o que enxergavam como pontos positivos e negativos das aulas remotas de LI (Responda: "O que você

\footnotetext{
${ }^{3}$ A título de detalhamento, em relação aos materiais didáticos de que nos servimos para as aulas de estágio, no primeiro caso, utilizamos o livro New Headway pré-intermediário, de autoria de John e Liz Soars (2011), em sua terceira edição, especificamente a unidade 5. Nessa seção do livro, tratam-se assuntos variados, como padrões verbais, formas verbais de futuro e adjetivos sobre sentimentos e sensações. Esses assuntos foram abordados tanto em exercícios gramaticais quanto em atividades de escuta (listening) e leitura. Já para a outra aula, mais avançada, servimo-nos do livro Ready for FCE, produzido por Roy Norris, na edição de 2013. Nas aulas de estágio, foi estudada a unidade 5, mais precisamente os tópicos que envolviam pronomes relativos e relative clauses. Esse material preparatório para o FCE (First Certificate of English) propunha atividades variadas, tanto de resolução de exercícios gramaticais, quanto atividades de leitura e de conversação.
} 
considera como aspectos positivos e negativos do ensino remoto de Língua Inglesa?" "Do que você gosta e/ou desgosta?"), os alunos escreveram:

QUADRO 1. Respostas dos alunos sobre suas percepções a respeito dos aspectos positivos e negativos do ensino remoto de língua inglesa

\begin{tabular}{|c|c|c|c|}
\hline Alunos & $\begin{array}{l}\text { Respostas sobre } \\
\text { aspectos positivos }\end{array}$ & $\begin{array}{l}\text { Respostas sobre } \\
\text { aspectos negativos }\end{array}$ & $\begin{array}{l}\text { Respostas que misturam } \\
\text { aspectos positivos e negativos }\end{array}$ \\
\hline A1 & $\begin{array}{l}\text { Sem deslocamento, } \\
\text { comodidade, conforto }\end{array}$ & $\begin{array}{l}\text { Problemas de conexão, áudio, } \\
\text { falta de privacidade às vezes, } \\
\text { falta de concentração, me distraía } \\
\text { facilmente }\end{array}$ & $\begin{array}{l}\text { Gosto de estar em casa, } \\
\text { confortável. Não gosto por, às } \\
\text { vezes, não entender bem }\end{array}$ \\
\hline A2 & $\begin{array}{l}\text { A comodidade de estar em } \\
\text { casa }\end{array}$ & $\begin{array}{l}\text { A principal dificuldade foi a falta de } \\
\text { contato físico }\end{array}$ & $\begin{array}{l}\text { Gosto de ficar em casa, não gosto } \\
\text { da falta da presença }\end{array}$ \\
\hline A3 & $\begin{array}{l}\text { Deslocamento como } \\
\text { facilidade prevaleceu }\end{array}$ & Queda de conexão & $\begin{array}{l}\text { Gosto de tudo no ensino remoto. Ele } \\
\text { facilitou deslocamento, melhorou a } \\
\text { alocação do tempo }\end{array}$ \\
\hline A4 & Economia de tempo & Falhas na conexão & $\begin{array}{l}\text { Gosto da praticidade do remoto, } \\
\text { mas sinto falta da interação } \\
\text { presencial com o professor }\end{array}$ \\
\hline A5 & $\begin{array}{l}\text { Horários que puderam ser } \\
\text { adequados, a aula poderia } \\
\text { ser realizada em qualquer } \\
\text { local e não apenas dentro de } \\
\text { uma sala }\end{array}$ & $\begin{array}{l}\text { Adaptação ao novo modo de ensino } \\
\text { (que geralmente era só presencial) }\end{array}$ & $\begin{array}{l}\text { É interessante pois não fica "preso" } \\
\text { a uma sala de aula e para ter } \\
\text { acesso a aula basta conseguir se } \\
\text { conectar, porém, por outro lado, a } \\
\text { falta de uma "rotina" e um local } \\
\text { adequado acaba fazendo com que } \\
\text { haja maior dispersão durante a } \\
\text { aula, tirando a atenção naquele } \\
\text { momento }\end{array}$ \\
\hline
\end{tabular}

Quadro elaborado pelos autores, 2020.

\section{Trajeto analítico}

A pergunta motivadora da discussão foi formulada para ser abrangente, a fim de não limitar as respostas dos sujeitos-alunos, que foram, no geral, bastante sucintas. Chamou nossa atenção que nenhuma dos respondentes mencionou exemplos concretos voltados ao aprendizado de LI em relação às facilidades e dificuldades promovidas pelas aulas online. Seus comentários giram em torno de questões técnicas ("falhas de conexão"; "problemas de conexão, áudio"), afetivas ("falta da presença"; "falta de contato físico"), cognitivas ("falta de concentração"; "não entender bem"; "maior dispersão durante a aula") e de mobilidade ("sem deslocamento"; "ficar em casa"; "economia de tempo").

Dos comentários dos alunos, notamos como regularidade temática que a vantagem em comum é ficar em casa. Levanta-se o argumento da comodidade, que não deixa de ter custos: duas 
alunas mencionam que nem sempre entendiam bem as aulas a distância, que geravam dificuldades de concentração, além de outro elemento pertinente que é a privacidade, ou melhor, a falta dela. Isso faz lembrar que não estamos no espaço previsto e institucionalizado do estudo, a sala de aula na escola, mas no ambiente familiar, da casa, que é geralmente dividido com outros familiares ou amigos. A problemática do espaço é relevante porque as formas discursivas de ocupá-los mudam: a casa passa a ser o espaço necessário do trabalho (para os professores) e do estudo (para os alunos). A separação entre um e outro se torna nublada, dificultando a distinção do que é específico de cada um, daquilo que torna um "local adequado" à aprendizagem, como escreve uma aluna. Estar (fisicamente) em casa já não significa estar (afetivamente) em casa.

Expandindo essa reflexão, dirigimo-nos a Gao e Zhang (2020), cujo foco de análise recaiu sobre as impressões de professores sobre o ERE. Preocupados em entender como os professores de LI na China têm construído sentidos para o ensino durante a pandemia, os pesquisadores relatam que, além dos problemas já comuns de falhas de conexão com a internet e falta de conhecimentos tecnológicos dos professores; outra relevante observação feita pelos docentes entrevistados diz respeito à preocupação com um ensino "delivery", que demanda de professores e alunos, em aulas síncronas e assíncronas, uma espécie de disponibilidade ininterrupta.

Essa preocupação é expressa também por Saraiva et al. (2020), ao mostrar que a docência tem sido levada à exaustão com o ensino remoto. Muitos professores têm sofrido com as demandas incessantes de preparação de aulas, contato com alunos, cursos de aperfeiçoamento, que extrapolam seus horários oficiais de trabalho. O regime $24 / 7$ da sociedade que não dorme dificulta que professores e alunos possam ter tempo de significar vivências tão radicalmente novas em suas vidas.

A docência nos tempos de pandemia é uma docência exausta, ansiosa e preocupada. Que quer acertar, mas que avança no meio da incerteza e da adversidade - e que não tem a menor ideia do caminho. Como todos, os professores estão imersos em uma névoa e seguem através dela, buscando fazer o melhor. (SARAIVA et al., 2020, p. 17).

Saraiva et al. (2020), retomando os conceitos foucaultianos de sociedade de disciplina e de sociedade de vigilância, ainda alertam para o fato de que cada vez mais estamos à mercê de dispositivos eletrônicos, que regulam nosso modo de vida. Com a disseminação do coronavírus, essa dependência parece aumentar, na fiscalização de horários, cumprimento de atividades, necessidade sem fim de um know-how irrefletido. O que resulta disso, de acordo com os autores, é a crescente solidão dos sujeitos, física e emocional.

Porém, como afirma Pêcheux (1995, p. 304), "não há dominação sem resistência”, o que produz efeitos na prática docente. Segundo comentam Saraiva et al. (2020), professores, incentivados por seus sindicatos, são encorajados - como de direito - a não trabalhar além de seu horário previsto, como uma forma de contra-conduta para dirimir a exaustividade imposta.

Outro ponto levantado nos comentários dos alunos foi o de problemas gerados pelas falhas de conexão, que interromperam as aulas em alguns momentos. Uma vez que não há discurso que circule fora de um "meio material" (DIAS, 2018), como redes sociais, aplicativos, espaço urbano etc., diremos que uma das especificidades da aula online é sua dependência ao meio 
material digital, da conexão com a internet, do bom funcionamento de aparelhos eletrônicos, das plataformas de vídeo e chat, que escapam ao nosso controle e lembram-nos de que estamos sujeitos ao digital.

O meio material aponta para as condições reais de existência (social, econômica, cultural...) dos sujeitos-alunos. Na situação de estágio relatada, não perdemos de vista que nos referimos ao contexto de ensino privado, que aponta para condições socioeconômicas diferentes daquela do ensino público, particularmente no que envolve o acesso a recursos tecnológicos. Mas não só: acesso a uma boa alimentação, acesso a um espaço e/ou tempo reservado para estudos. E mais: no dizer de Orlandi (2008), o acesso puro e simples, embora indispensável, também não é suficiente para uma transformação efetiva do ensino, posto que "não é o acesso ao instrumento em si que muda as relações sociais, mas o modo de sua apropriação, no qual estão atestadas as marcas de quem se apropria dele" (ORLANDI, 2008, p. 36-37).

Não podemos ceder ao fácil discurso do novo, das novas tecnologias que vêm solucionar todos os problemas, assim como não cabe repetir acriticamente os mesmos processos, os mesmos métodos, os mesmos discursos. O caminho é mais tenso, intervalar, pois exige a reinvindicação necessária ao acesso, sem ignorar, no entanto, a importância da produção de outros saberes, de outros lugares possíveis de ação.

Do lugar analítico do discurso, compreendemos que a questão central passa pela apropriação das materialidades discursivas, no sentido que Orlandi (2005) dá ao termo, o encontro da ordem da linguagem com a ordem da história. Esse processo pode se dar no reconhecimento de que, se o digital é um meio propício para o trabalho com diferentes linguagens além da verbal, isso deve acontecer de forma a despertar no aluno diferentes possibilidades de leitura do mundo, modos distintos de interpretar a realidade social em que está inserido. Além de dar condições de explorar fotografias, músicas, gestualidades, emojis, o ciberespaço permite a "articulação material" de diferentes linguagens, potencializando e complexificando os processos de leitura.

Entre as potencialidades do ensino de línguas, o multiletramento já vem sendo estudado como método de ensino, por exemplo, nos trabalhos de Lemke (2006), a respeito de letramento crítico, e de Cope e Kalantzis (2000), que propuseram multiletramentos como forma de ressignificar o ensino para o futuro. Com aporte na teoria discursiva, uma forma de propiciar essa apropriação material que tem sido importante em nossa prática de ensino de LI é pedir aos alunos que questionem as imagens que acompanham os textos de seus materiais, perguntando que sentidos elas constroem para além da complementaridade do texto verbal. Além disso, encorajamos os alunos a trazerem exemplares de língua para a sala de aula (músicas, vídeos, jogos), chamando-os para uma participação efetiva em seu próprio aprendizado - sem deixar de lado, obviamente, as demandas curriculares - para serem, de fato, sujeitos de seu saber.

O último comentário dos estudantes toca na temática da ausência, em que dois alunos mencionam a falta da presença física, repetindo e insistindo na importância de interagir presencialmente. E que nos leva a indagar: o que há na presença que intervém no ensino?

É intrigante observar que a dinâmica de aula era similar antes da pandemia, posto que eram individuais, frente a frente com os alunos na sala de aula. Embora esse padrão se mantivesse, lidar com o ERE impôs dificuldades na materialização da aula, na interlocução entre professor- 
-aluno, professor-conteúdo e aluno-conteúdo. Houve uma mudança na materialidade das relações, mediadas pela tela, que não é indiferente na instância da significação e, consequentemente, no processo de ensino.

Em termos analíticos, entendemos que a presença dos corpos, em relação material na sala de aula, favorece a assunção da posição de sujeitos-alunos e a convivência produtiva de sujeitos em sociedade. Ao participar das aulas em casa, no quarto, muitas vezes com a roupa de dormir, não se separa lar de escola, o que pode causar entraves no envolvimento com a aula, no gerenciamento das demandas discursivas. Nesse exemplo, a presença (ausente) se instabiliza. O ERE parece carecer do aspecto socializante do ensino, dificultando a partilha mútua, o contato do olhar, da voz, do abraço, que não deixam de ter implicações para o processo de ensinar e aprender. Sem falar em tópicos de saúde mental, de solidão, problemas sérios que merecem atenção e futuras investigações.

Rumando para o fim, acrescentamos a esta seção outras possibilidades produtivas que o digital oportuniza para o ensino. Por exemplo, em seu estudo sobre as potencialidades de intervenção em aulas de LI durante a pandemia, Yi e Jang (2020) sugerem o ensino translingual, que contempla tanto o uso da língua materna quanto da língua alvo, desde que a passagem entre elas não seja estanque e truncada, mas fluida. Outro recurso possibilitado pela internet é o ensino colaborativo, com professores de outras instituições e mesmo outros países, nativos de LI. Nesse caso, a aula de língua passa a ser também o palco para a interlocução entre culturas diferentes.

Por meio de sua revisão da literatura, Oliveira et al. (2020) sustentam que tanto o aumento de horas em aula quanto a implementação de tecnologias no ensino, apesar de soarem como estratégias promissoras, mostram efeitos positivos modestos em estudos em larga escala feitos antes e durante a pandemia de COVID-19. Conforme os autores, isso mostra que não há solução fácil, sendo preciso levar em consideração a estruturação do currículo, a formação dos professores, as particularidades regionais, os diferentes níveis econômicos dos alunos, entre outros aspectos.

Não se trata apenas de disponibilizar equipamentos e internet (também importantes), mas pensar em formas de inserir as tecnologias no funcionamento pedagógico. Indo nessa direção, Oliveira et al. (2020) mencionam, como caminho de intervenção, um investimento em tutores para grupos reduzidos de alunos, que deve ser feito com um planejamento orçamentário estruturado, tendo em vista as dificuldades econômicas que assolam o país. Tal planejamento precisa proceder com um diagnóstico das condições de aprendizado dos alunos, para, com isso, propor ações pedagógicas mais efetivas.

[...] a partir daí, intervenções robustas e promissoras que incluem, do lado pedagógico, o ensino estruturado, o uso de métodos adequados de alfabetização, o uso estratégico dos deveres de casa e de programas de leitura. O melhor uso do tempo consiste na redução do absenteísmo e, para os alunos com mais dificuldade, programas intensivos de tutoria em pequenos grupos. (OLIVEIRA et al., 2020, p. 566).

Por isso, insistindo em uma perspectiva discursiva, falar em capacitação tecnológica é chegar até um limite, que é o da aplicação por si mesma, retornando à ilusão de que a competência seja um bloco homogêneo compartilhado pelos sujeitos, alunos e professores. A ideia de que se possa dominar a tecnologia para dominar uma língua e, assim, uma cultura impõe o risco da homo- 
geneização, do apagamento das diferenças. Para De Nardi (2009), não há uma homogeneidade nem linguística nem cultural para que possa haver tal apreensão, tendo em vista que nossa participação na língua e na cultura é sempre parcial. Competência e capacitação implicam a unidade, o todo. Rejeita-se o múltiplo, o não-todo, tão significativos para uma abordagem discursiva de ensino, que compreende a alteridade enquanto o ponto de referência da identidade e também da cultura. Novamente é De Nardi (2009) quem argumenta que o ensino e a aprendizagem de uma língua, assim como de uma cultura, só fazem sentido se as entendermos como elementos complexos e contraditórios.

Pêcheux (1990) postula que o terreno da AD coloca em causa o sujeito pragmático, que tem a urgência de um mundo semanticamente estável e normal. É próprio do discurso sua dispersão e incompletude, que incomodam o modo de pensar positivista ocidental. O esforço de um professor interessado nos aspectos discursivos de seu trabalho como educador deve, portanto, gravitar em torno do reconhecimento da historicidade da língua e de seu ensino.

Para M. Grigoletto (2012), é preciso ensinar a língua, mas também ensinar "sobre" a língua. Ensinar a refletir sobre ela, no limiar equívoco entre o saber pedagógico (instruir) e o saber científico (refletir). Vemos nas disciplinas de estágio nos cursos de licenciatura justamente uma oportunidade fecunda para aliar conhecimentos científicos sobre a língua a saberes práticos de vivências em sala de aula (ainda que virtuais).

Conforme sugere Lacerda (2019, p. 54), é papel do professor buscar "oferecer condições para que seus alunos deem sentido a suas leituras por meio da significação de suas próprias vivências (...) sem desconsiderar a historicidade da materialidade textual". Para a presente reflexão, expandimos essa compreensão para falar da materialidade da aula remota.

Diante do digital como possibilidade manifesta no ensino de línguas, nossa contribuição específica é propor a reflexão sobre "os efeitos metafóricos do ensino presencial ao virtual". A passagem da sala para a plataforma online, do quadro para a tela, redimensiona a língua e seu ensino. Desse modo, apontamos o desafio de trabalhar (n)a metáfora, que em uma visada discursiva significa "transferência", deslizamento dos sentidos afetados pela relação com os outros (e com o Outro interdiscursivo). Consoante Orlandi (2005, p. 23), a metáfora "é assim constitutiva do sentido" porque representa um "fenômeno semântico - a deriva - produzido por uma substituição" que "situa a questão do funcionamento face à articulação entre língua e discurso".

Para nós, o ato de ensinar LI remotamente clama pelo "reconhecimento dos efeitos metafóricos da materialidade digital no ensino", reconhecer a historicidade dos processos de substituição e de deriva. O contrário disso seria o decalque, apagando as condições de produção específicas do ensino. Como escreve Dias (2018, p. 141),

A tecnologia digital como condição de produção do ensinar e aprender compreende o fato de que o conhecimento se produz em redes de acesso, em que a conectividade, a velocidade, a personalização (seu jeito de aprender) (ou uniformização?) e a organização horizontal das coisas-a-saber (clique na aba edu e escolhas as aulas por matéria), são determinantes. (DIAS, 2018, p. 141).

Ao considerar ensino (de línguas) como um acontecimento discursivo e a aula como evento material, não estacionamos nos sentidos de capacitação, nem mesmo de mera adição (digital 
+ ensino) ou transposição metodológica, que reduziriam o processo a uma "caricaturização da própria educação" (DIAS, 2018, p. 150).

Trata-se, sim, de um processo de metaforização em que o digital e o processo de ensino-aprendizagem se perturbam para produzir outros processos de significação para o conhecimento, a escola, a aprendizagem, numa "articulação vertical" capaz de deslocar as significações. Com isso, não se corre o risco de significar o ensino, a Educação pelo digital, numa articulação horizontal dos sentidos, que coloca o sujeito num espaço estabilizado, imposto do exterior como uma coerção. (DIAS, 2018, p. 150).

Concordamos com E. Grigoletto (2011b), quando escreve que o virtual afeta as posições antes estáveis de professores e alunos. Ainda que circule a evidência do digital como espaço propício para a interlocução, ela muitas vezes não se efetiva. Depreendemos isso também nas falas dos alunos, ao questionarem aspectos técnicos e cognitivos. Mudando a materialidade e o espaço de dizer, transforma-se as formas de acessar esse (direito de) dizer. Contudo, não basta que as formas mudem, é preciso que se desloquem os sentidos, desafiem-se os modos de enunciação, reformulem-se os acontecimentos discursivos.

Falar outra língua é assumir outras redes de memória (entendida como virtualidade de significações). Além da aplicação pragmática, que não negamos ter seu papel, permanece a exigência de uma recolocação, a assunção de outra tomada de posição do sujeito na língua estrangeira, língua do outro (DE NARDI, 2003). Fazer do aluno mais do que falante, mas sujeito nessa língua exige que se saia do espaço familiar da língua materna para se arriscar na língua-outra, o que constitui um movimento repleto de descolamentos, deriva do sentido na língua e na história. Enfim, é atentar-se para as movências do sujeito no discurso e no percurso de ensino.

Não pode ser esquecido o papel do professor, que é convocado a agir com coragem em sua prática de ensino, mesmo ciente dos desmantelamentos que a categoria vem sofrendo no país. Ao atuar criticamente com instrumentos digitais voltados ao ensino, professores e alunos podem repensar seus lugares, seus modos de pensar e agir e o valor que reconhecem na escola. $\mathrm{O}$ ensino de LI, mas também a educação no geral, atravessados - como um corte - pelo digital, devem aprender a metaforizá-lo para não o repetir levianamente.

\section{Considerações finais/preliminares}

Encerramos este texto, mas as demandas do e para o ensino permanecem. Não foi nossa pretensão esgotar o tema, aliás muito recente e polêmico; o que propusemos foi relatar uma experiência com vistas a analisar os desafios impostos, bem como apontar caminhos possíveis de reflexão. Reconhecemos as limitações da análise proposta, entre elas o fato de partir de uma experiência de ensino específica e de comentários de apenas cinco alunos acerca do ERE em contexto de pandemia. Contudo, a relevância da discussão permanece, tanto explorando o trabalho e as indagações de professores quanto os dizeres e os anseios de alunos, todos sujeitos de linguagem e, portanto, sujeitos desejantes. 
O que depreendemos dessas análises preliminares é que, em meio aos desafios trazidos pela pandemia de COVID-19, o ensino de LI, em específico, assim como a educação, no geral, não ficam isentas. Entre problemas sociais, emocionais e tecnológicos, chamamos a atenção para a questão da presença-ausente no ensino remoto, que, como todo fato discursivo, possui sua materialidade específica. Por meio de nosso gesto analítico, entendemos que uma tal materialidade produz efeitos concretos no ensino, o que nos levou a falar da indispensabilidade do efeito metafórico sala de aula física/virtual. Em sintonia com a proposta pecheuxtiana de apropriação material dos instrumentos científicos (PÊCHEUX, 1995), cabe a nós, professores, a apropriação material dos instrumentos de ensino.

As consequências ainda estão para serem vistas, embora muito já seja possível divisar. Como educadores, o que podemos e devemos fazer é buscar formas de tentar mitigar os efeitos deletérios da pandemia sobre o ensino, particularmente o de línguas, que nos toca mais de perto, sem ignorar a necessidade que todos temos, nessa situação pandêmica, de reconhecer nossos limites. Mais do que apenas adaptarmo-nos, cremos fundamental reconhecer que o digital transforma as práticas de ensino e trabalhar sobre esses sentidos. Enfim, como argumentamos, reconhecer os efeitos metafóricos e investir sobre eles.

\section{REFERÊNCIAS}

CALVO, L. C.; RIOS-REGISTRO, E. S.; OHUSCHI, M. G.; EL KADRI, M. S. Percepções de estudantes e profissionais chineses sobre o status do Inglês como Língua Franca. Revista X, v.2, p. 1-21, 2009.

COPE, B.; KALANTZIS, C. Multiliteracies: literacy learning and the design of social futures. London: Routledge, 2000.

DE NARDI, F. S. Entre a lembrança e o esquecimento: os trabalhos da memória na relação com língua e discurso. Organon, v.17, n.35, p. 63-85, 2003.

DE NARDI, F. S. Língua, cultura e competência: questões para o ensino e o discurso. In: INDURSKY, F.; FERREIRA, M. C. L.; MITTMANN, S (Orgs.). O discurso na contemporaneidade: materialidades e fronteiras. São Carlos: Claraluz, 2009, p. 125-132.

DIAS, C. A discursividade da rede (de sentidos): a sala de bate-papo hiv. Tese (Doutorado em Linguística) Universidade Estadual de Campinas, Campinas, 2004.

DIAS, C. Análise do discurso digital: sujeito, espaço, memória e arquivo. Campinas: Pontes, 2018.

ESTRELLA, Bianca; LIMA, Larissa. CNE aprova diretrizes para escolas durante a pandemia. Portal MEC. 28 de abril de 2020. Disponível em <http://portal.mec.gov.br/busca-geral/12-noticias/acoes-programas-e-projetos-637152388/89051-cne\%C2\%AC-aprova-diretrizes-para-escolas-durante-a-pandemia $>$. Acesso em: 23/ Dez/2020.

GAO, L. X.; ZHANG, L. J. Teacher learning in difficult times: examining foreign language teachers' cognitions about online teaching to tide over COVID-19. Frontiers of Psychology, v.11, p. 1-14, 2020.

GRIGOLETTO, E. Do discurso político às novas tecnologias: um percurso sobre o objeto de estudo da Análise do Discurso. Organon, v.24, n.48, p. 1-13, 2011 a. 
GRIGOLETTO, E. O ensino a distância e as novas tecnologias: o funcionamento do discurso pedagógico nos Ambientes Virtuais de Aprendizagem. Eutomia, v.1, n.7, 254-271, 2011 b.

GRIGOLETTO, M. Mídia e Discurso sobre o ensino de línguas na escola: circulação de saber e posição-sujeito para o aluno. Eutomia, v.1, n.9, p. 308-320, 2012.

LACERDA, G. H. Memes na aula de leitura: uma proposta discursiva. In: DI RAIMO, L. C. D.; STEFANIU, L. F. (orgs.). N(os) movimentos de uma articulação: análise de discurso e ensino. Campinas: Pontes, 2019, p. 37-62.

LEMKE, J. Toward Critical Multimedia Literacy: Technology, Research and Politics. In: MCKENNA, M. C. (org.). International handbook of literacy and technology. Vol.2. New Jersey: Lawrence Erlbaum Associates, 2006.

MOORE, M.; KEASLEY, G. Distance education: a systems view. Belmont: Wadstown Publish Company, 1996.

OLIVEIRA, J. B. A.; GOMES, M.; BARCELLOS, T. A COVID-19 e a volta às aulas: ouvindo as evidências. Ensaio: Avaliação e Políticas Públicas em Educação, v.28, n.108, p. 555-578, 2020.

ORLANDI, E. Discurso e texto: formulação e circulação dos sentidos. Campinas: Pontes, 2005.

ORLANDI, E. Discurso e leitura. 8. ed. São Paulo: Cortez, 2008.

PÊCHEUX, M. Discurso: estrutura ou acontecimento. Campinas: Pontes, 1990.

PÊCHEUX, M. Semântica e discurso: uma crítica à afirmação do óbvio. Campinas: Editora da Unicamp, 1995.

Rede Brasil Atual. Disponível em <https://www.redebrasilatual.com.br/educacao/2020/10/reabertura-escolas-sao-paulo/>. Acesso em: 20/nov.2020.

SARAIVA, K.; TRAVERSINI, C.; LOCKMANN, K. A educação em tempos de COVID-19: ensino remoto e exaustão docente. Práxis Educativa, v.15, p. 1-24, 2020.

UNESCO. A Comissão Futuros da Educação da Unesco apela ao planejamento antecipado contra o aumento das desigualdades após a COVID-19. Paris: Unesco, 16 abr. 2020. Disponível em: <https://pt.unesco. $\mathrm{org} /$ news/comissao-futuros-da-educacao-da-unesco-apela-ao-planejamento-antecipado-o-aumento-das $>$. Acesso em: 25 nov. 2020.

YI, Y.; JANG, J. Envisioning possibilities amid the COVID-19 pandemic: implications from English language teaching in South Korea. TESOL Journal, n.11, p. 1-5, 2020. 